\title{
Preparation of Polyaniline/ZnO Films by Electrochemical Polymerization
}

\author{
Yuki Kaitsuka, Hiromasa Goto* \\ Division of Materials Science, Faculty of Pure and Applied Sciences, University of Tsukuba, Tsukuba, Japan \\ Email: "gotoh@ims.tsukuba.ac.jp
}

Received 18 January 2016; accepted 17 February 2016; published 23 February 2016

Copyright (C) 2016 by authors and Scientific Research Publishing Inc.

This work is licensed under the Creative Commons Attribution International License (CC BY).

http://creativecommons.org/licenses/by/4.0/

(c) (i) Open Access

\section{Abstract}

A series of polyaniline (PANI)/zinc oxide ( $\mathrm{ZnO}$ ) nano-particle (diameter $70 \mathrm{~nm}$ ) composite films were prepared by electrochemical polymerization in the presence of $\mathrm{ZnO}$ nanoparticle. Furthermore, PANI-Zn0/PVA (PVA = polyvinyl alcohol) double-layer system was prepared. We first report preparations of a photocatalyst/conducting polymer light absorber by using $\mathrm{ZnO}$ nano-particles.

\section{Keywords}

\section{Light-Driven, Nano-Particle, Optical Activity}

\section{Introduction}

Zinc oxide ( $\mathrm{ZnO})$ is well known as a photocatalytic inorganic material [1]. It has been investigated for applications in photocatalytic devices, photovoltaics, gas sensors, and piezoelectric energy harvesters [2]-[5]. ZnO has wide band gap (3.37 eV) and hole-electron binding energy of $60 \mathrm{mV} \mathrm{[6].} \mathrm{ZnO}$ can be used to collect high-energy photons (UV light) due to the large band gap. In order to expand its response range from UV light to visible light, employment of hetero-structure with narrow band gap semiconductors or dyes as sensitizers in combination with $\mathrm{ZnO}$ has been reported [6]-[8]. $\mathrm{ZnO}$ is a candidate for incorporation as a nano-particle within a polymer film.

Polyaniline (PANI) is one of the most remarkable conjugated polymers due to its relative ease of preparation in water solvent, environmental and thermal stability, and tunable conductivity [9]. Also, PANI thin films can be fabricated easily through various methods such as electrochemical polymerization, solution casting technique, and sol-gel spin coating [10]-[12]. It has promise for a large variety of applications, such as light emitting diodes, corrosion-inhibiting paint, and electro-chromic devices [13]-[15]. In previous research several reports focused

"Corresponding author.

How to cite this paper: Kaitsuka, Y. and Goto, H. (2016) Preparation of Polyaniline/ZnO Films by Electrochemical Polymerization. Open Journal of Polymer Chemistry, 6, 1-7. http://dx.doi.org/10.4236/ojpchem.2016.61001 
on UV emission and photocatalytic activity of PANI/ZnO composite [6] [16]. Morphological changes in organic photoactive materials upon UV irradiation have been studied [17]-[19]. This paper reports preparation of optically active PANI/ZnO composite films, PANI-ZnO/polyvinyl alcohol double-layer films for application toward light-tunable devices.

\section{Materials}

Aniline (Wako, Japan) was first purified by distillation. (+)-Camphor sulfonic acid (Tokyo Chemical Industry (TCI), Japan), (-)-camphor sulfonic acid, sulfuric acid (TCI) and ammonium peroxodisulfate (APS, Kanto Chemical, Japan), zinc oxide nano-particles of diameter $70 \mathrm{~nm}$ were used as received.

\section{Synthesis}

\subsection{PANI (CSA)-ZnO Composite}

Electrochemical polymerization in the presence of $\mathrm{ZnO}$ nano-particles was performed to produce PANI (CSA)$\mathrm{ZnO}$ composites, Films 1 (b-d) and 2 (b-d). An electrolyte was prepared by addition of the aniline and (+)-camphor sulfonic acid (or (-)-camphor sulfonic acid) as chiral dopants and nano-ZnO particles to distilled water (Table 1). Polymerization was performed by applying direct voltage (DC) at $3.0 \mathrm{~V}$. Then, the resultant film was washed with distilled water and methanol to remove low molecular weight fractions and residual $\mathrm{ZnO}$ on the surface. The structure is illustrated in Figure 1(a).

PANI doped with CSA film (Films 1a and 2a) without $\mathrm{ZnO}$ was prepared with the same procedure as preparation of Films 1 (b-d) and 2 (b-d).

\subsection{PANI (CSA)-Zno/PVA Layer (Double-Layer)}

Electrochemical polymerization in without $\mathrm{ZnO}$ nano-particles was performed. The resultant film was immersed into a solution of dispersed $\mathrm{ZnO}$ in water/PVA (PVA = polyvinyl alcohol) producing a film with double-layer structure consisting of PANI (CSA) and ZnO/PVA.

First, chiral-PANI films were prepared on the anode side of ITO glass electrodes by electrochemical polymerization with no $\mathrm{ZnO}$ electrolyte solution. $\mathrm{ZnO}$ was dispersed in $0.1 \mathrm{wt} \%$ PVA solution. Here, PVA is employed as a matrix for $\mathrm{ZnO}$. Then, the film was immersed into the dispersion. After drying, the chiral-PANI/ZnO double-layer film (Film 3a and 3b) was obtained. Washing was performed with the same procedure as preparation of Films 1(a-d). The structure is indicated in Figure 1.

Table 1. Preparation of PANI/ZnO and PANI-ZnO/PVA films.

\begin{tabular}{|c|c|c|c|c|c|c|}
\hline \multirow[b]{2}{*}{ Category } & \multicolumn{6}{|c|}{ Electrolyte solution } \\
\hline & Film & $\mathrm{CSA}^{\mathrm{a}}$ & $\mathrm{H}_{2} \mathrm{O}(\mathrm{mL})$ & Aniline (mg) & $\mathrm{ZnO}$ (mg) & $\begin{array}{l}\mathrm{ZnO} \text { conc/PVA in } \\
\text { water } \operatorname{soln}^{\mathrm{e}}(\mathrm{M})\end{array}$ \\
\hline \multirow{6}{*}{ PANI/ZnO composite } & Film $1 b^{b}$ & & 1 & 20 & 4 & \\
\hline & Film $2 \mathbf{b}^{\mathrm{b}}$ & & 1 & 20 & 4 & \\
\hline & Film 1c & & 1 & 20 & 12 & \\
\hline & Film 2c ${ }^{\mathrm{b}}$ & & 1 & 20 & 12 & \\
\hline & Film 1d ${ }^{\mathrm{b}}$ & & 1 & 20 & 18 & \\
\hline & Film 2d $d^{\mathrm{b}}$ & & 1 & 20 & 18 & \\
\hline \multirow{2}{*}{ PANI-ZnO/PVA (double-layer) } & Film $3 a^{c}$ & & 1 & 20 & & 0.06 \\
\hline & Film $3 \mathbf{b}^{\mathrm{c}}$ & & 1 & 20 & & 0.006 \\
\hline
\end{tabular}

a) Camphor sulfonic acid (CSA). (+) and (-) represent optical activities. b), c) Abbreviations “1” and "2" correspond to (+)-CSA and (-)-CSA employed in the electrochemical polymerization, respectively. b) Electrochemical polymerization in the presence of ZnO nano-particles. c) Electrochemical polymerization with no ZnO nano-particles. Resultant films were immersed in the ZnO dispersed PVA in the water solution to deposit $\mathrm{ZnO}$ /PVA layer on the surface of the optically active PANI films. PVA = polyvinyl alcohol. d) Concentration of ZnO dispersion solution for immersion of PANI films. e) Dispersion concentration in $0.1 \mathrm{wt} \%$ PVA/water solution (M). 
(a)

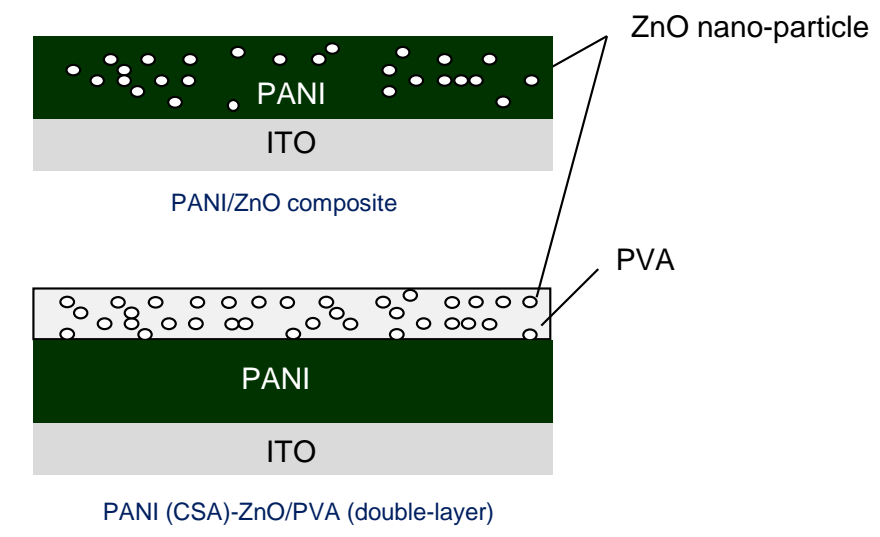

Figure 1. (a) PANI (CSA)-ZnO composite; (b) double-layer consisting of PANI (CSA) and ZnO/PVA layers. $\mathrm{PANI}=$ polyaniline, $\mathrm{PVA}=$ polyvinyl alcohol, CSA $=$ optically active $(+)$ or $(-)$-camphor sulfonic acid.

\section{Results and Discussion}

\subsection{Optical Spectroscopy}

Circular dichroism (CD) absorption spectroscopy measurements of the films were carried out to confirm optical activity. All of the films show Cotton effect in the CD. The signal intensities increase with increase of composition of $\mathrm{ZnO}$ in the PANI. Especially, Film 1d and Film 2d display clear and intense complementary mirror-image Cotton effect, shown in Figure 2. These films show intense CD signals compared with those of pure optically active polyanilines. This can be due to interaction between $\mathrm{ZnO}$ and the optically active main-chain (PANI-CSA) that amplify the chirality. Addition of large amounts of $\mathrm{ZnO}$ is required in the polymerization reaction because the resultant composite films cannot absorb all of the $\mathrm{ZnO}$ in the electrochemical polymerization. In other words, the yielding percentage of nano-ZnO in the PANI/ZnO composite can be low.

These film show optical absorption bands at $430 \mathrm{~nm}$ and at around $850 \mathrm{~nm}$ due to $\pi$ - $\pi^{*}$ transition of benzenoid segments and formation of polarons in quinoid segments respectively [20].

As for PANI-ZnO/PVA (Films 3a and 3b, double-layer film), an interface oxidation reaction between PANI and $\mathrm{ZnO}$ /PVA layers may occur; however, interfacial contact between $\mathrm{ZnO}$ and PANI via the PVA matrix may be low. So, photocatalytic doping of PANI with $\mathrm{ZnO}$ could not occur upon irradiation of UV light in this study.

\subsection{Morphology and EDS}

Scanning electron microscopy (SEM) images for Film 1d, 3a, and 3b are shown in Figure 3. In general, PANIdoped with CSA films show interconnected networks [21]. The films thus prepared display characteristic morphologies. Energy-dispersive X-ray spectroscopy (EDS) measurement result for Film 3a confirms the form of the film surface, because Film 3a has large amounts of $\mathrm{Zn}$ from $\mathrm{ZnO}$ (39.77 counts (a.u) in the component, Table 2). The EDS reveals that Film 1d contains small amounts of $\mathrm{ZnO}$. This result implies that the PANI incorporates a small amount of $\mathrm{ZnO}$ during the electrochemical polymerization process.

\subsection{IR}

The FTIR spectra of Film 2a after UV irradiation in water were recorded as shown in Figure 4. The incorporation of CSA into the polyaniline chain was confirmed with FTIR. The characteristic IR absorption peak at 1574, $1497,1302,1249,1148$, and $817 \mathrm{~cm}^{-1}$ were found in all the spectra. These peaks are attributed to quinonoid (Q) $\mathrm{C}=\mathrm{C}$ stretching, benzenoid $(\mathrm{B}) \mathrm{C}=\mathrm{C}$ stretching, $v_{\mathrm{QBQ}} \mathrm{C}-\mathrm{N}$ stretching, $v_{\mathrm{BBB}} \mathrm{C}-\mathrm{N}$ stretching, aromatic $\mathrm{C}-\mathrm{H}$ in plane bending vibration, and $\mathrm{C}-\mathrm{H}$ out-of-plane bending vibration of PANI, respectively [21]. Protonated polymer was confirmed with the peak at $1734 \mathrm{~cm}^{-1}\left(\mathrm{C}=\mathrm{O}\right.$ stretching vibration) and $1047 \mathrm{~cm}^{-1}$ ( $\mathrm{SO}^{3-}$ vibration) derived from CSA. Spectra of the PANI layer are not changed upon the UV irradiation, indicating that the chemical structure of the PANI is not changed upon UV light irradiation. 


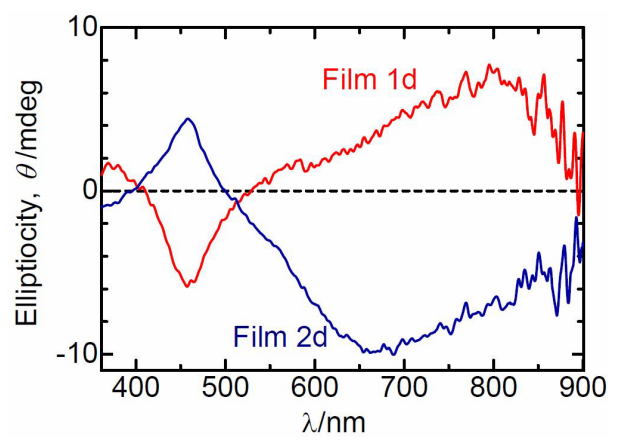

Figure 2. CD spectra of Film 1d and 2d.

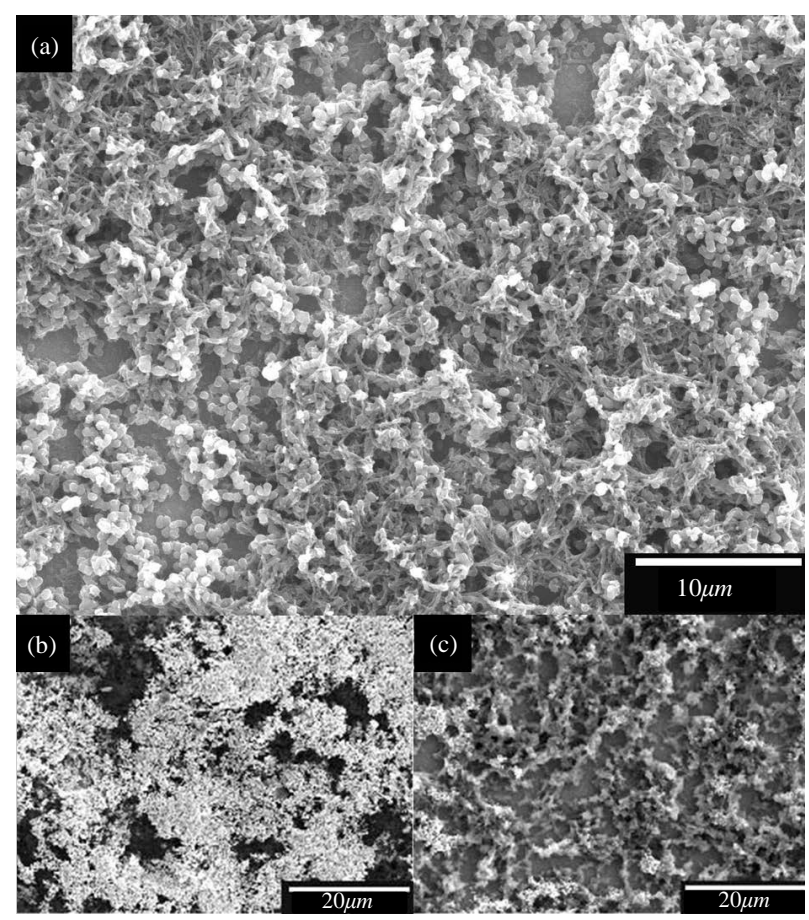

Figure 3. Scanning electron microscopy (SEM) images. (a) Film 1d; (b) Film 3a; (c) Film 3b.

Table 2. Energy dispersive X-ray spectroscopy (EDS) analysis for PANI/ZnO and PANI (CSA).

\begin{tabular}{lccccc}
\hline \multirow{2}{*}{ Film } & C & N & O & S & Zn \\
\cline { 2 - 6 } & & & Counts (arb. units) & \\
\hline Film 1d & 51.45 & 24.30 & 19.91 & 3.39 & 0.96 \\
Film 3a & 36.87 & 3.01 & 19 & 1.36 & 39.77 \\
\hline
\end{tabular}

\subsection{Thermography}

Figure 5 shows thermographic images of Film 3b on the ITO substrate upon infrared (IR, left) and ultraviolet (UV, right) light irradiation. The thermographic image upon irradiation of the IR light demonstrates that the film (Film $3 b$ ) absorbs visible range light and surface temperature is increased $\left(\Delta T=+5^{\circ} \mathrm{C}\right)$. On the other hand, the film absorbs UV light upon irradiation of UV light, and the surface does not reflect UV light, resulting no change of the surface temperature $\left(\Delta T=-5^{\circ} \mathrm{C}\right)$, although surrounding temperature is increased. PANI absorbs both the IR and the UV ranges, and $\mathrm{ZnO}$ absorbs UV light. So, ZnO enhances absorption of the UV light for the film. 


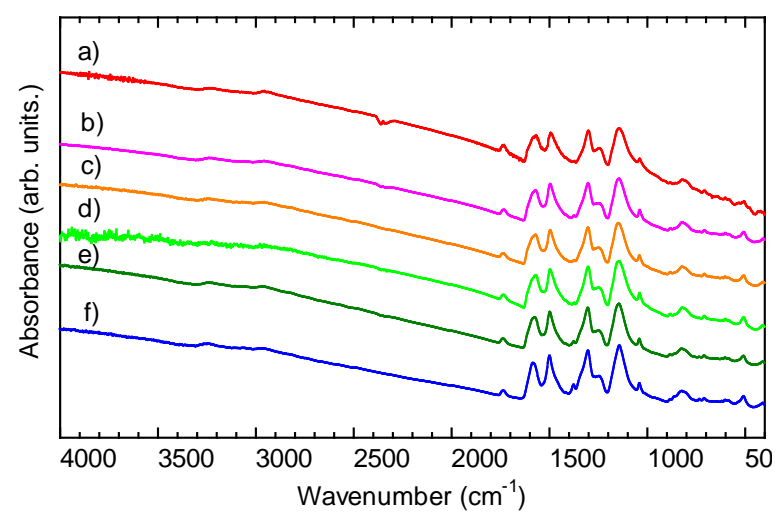

Figure 4. Fourier transform infrared (FTIR) spectra of Film 2a after UV irradiation. UV irradiation time is $0 \mathrm{~min}$ (a), $0.5 \mathrm{~min}$ (b), $1 \mathrm{~min}$ (c), $3 \mathrm{~min}$ (d), 5 min (e), and 10 min (f).

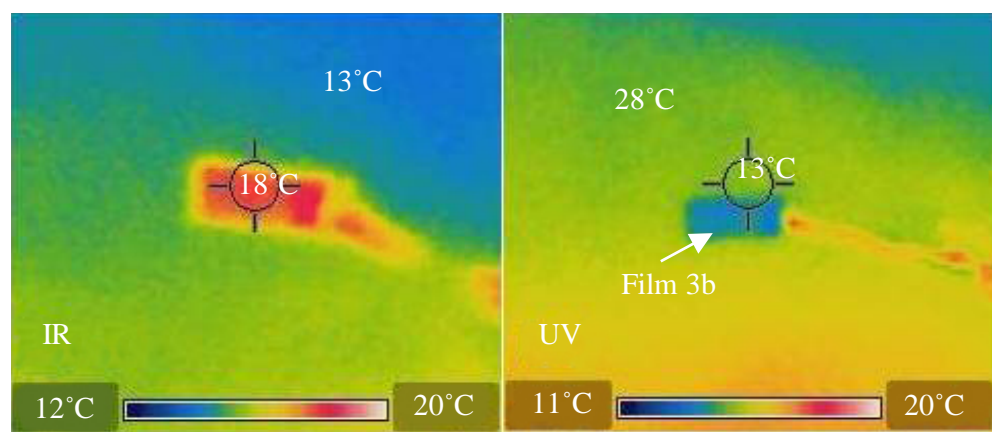

Figure 5. Themographies of Film 3b upon IR (left) and UV (right) irradiation.

\section{Conclusion}

We prepared PANI/ZnO composites by electrochemical polymerization and PANI-ZnO/PVA double-layer systems with electrochemical polymerization followed by immersion in ZnO/PVA water solution. Chemical polymerization of PANI in the presence of $\mathrm{ZnO}$ to prepare PANI/ZnO nanocomposites was carried out in previous work [22]. The combination demonstrates the ability of producing photocatalyst/conducting polymer thin films. Future research should pursue improvement of the interaction between PANI and ZnO nano-particles in the polymerization to obtain PANI incorporating larger amounts of $\mathrm{ZnO}$.

\section{Acknowledgements}

We would like to thank the Chemical Analysis Division Research Facility Center for Science and Technology of the University of Tsukuba for ESR measurements. This work was supported by the Kijima Laboratory of the University of Tsukuba for the IR measurements. This work was also supported by National Institute for Materials Science (NIMS) microstructural characterization platform for obtaining SEM images and EDS analyses. We thank Dr. Takeguchi, Station Director, Transmission Electron Microscopy Station, NIMS.

\section{Techniques}

Ultraviolet and visible (UV-vis) spectroscopy was recorded on a JASCO V-630 spectrophotometer. Circular dichroism (CD) spectroscopy was recorded on a JASCO J-720 spectrometer. An artifact detection/offset system was used for the measurements. Scanning electron microscopy (SEM) observations and energy-dispersive X-ray spectroscopy (EDS) were carried out by a JEOL JSM-7000F and JED-2200. Infrared (IR) absorption spectra were obtained using a Thermo Scientific NICOLET iS5 with the $\mathrm{KBr}$ method. Electron-spin-resonance (ESR) measurements were performed with a Bruker EMX-T ESR spectrometer. Thermographic images of the films 
were obtained with an FLIR i5 (FLIR Systems).

\section{References}

[1] Li, D. and Haneda, H. (2003) Morphologies of Zinc Oxide Particles and Their Effects on Photocatalysis. Chemosphere, 51, 129-137. http://dx.doi.org/10.1016/S0045-6535(02)00787-7

[2] Nair, M.G., Nirmala, M., Rekha, K. and Anukaliani, A. (2011) Structural, Optical, Photo Catalytic and Antibacterial Activity of Zno and Co Doped ZnO Nanoparticles. Materials Letters, 65, 1797-1800. http://dx.doi.org/10.1016/j.matlet.2011.03.079

[3] Izaki, M., Shinagawa, T., Mizuno, K., Ida, Y., Inaba, M. and Tasaka, A. (2007) Electrochemically Constructed P$\mathrm{Cu}_{2} \mathrm{O} / \mathrm{N}-\mathrm{ZnO}$ Heterojunction Diode for Photovoltaic Device. Journal of Physics D: Applied Physics, 40, 3326-3329. http://dx.doi.org/10.1088/0022-3727/40/11/010

[4] Ko, H.U., Mun, S., Min, S.K., Kim, G.W. and Kim, J. (2014) Fabrication of Cellulose ZnO Hybrid Nanocomposite and Its Strain Sensing Behavior. Materials, 7, 7000-7009. http://dx.doi.org/10.3390/ma7107000

[5] Song, J., Zhou, J. and Wang, Z.L. (2006) Piezoelectric and Semiconducting Coupled Power Generating Process of a Single ZnO Belt/Wire. A Technology for Harvesting Electricity from the Environment. Nano Letters, 6, 1656-1662. http://dx.doi.org/10.1021/nl060820v

[6] Eskizeybek, V., Sarı, F., Gülce, H., Gülce, A. and Avc1, A. (2012) Preparation of the New Polyaniline/ZnO Nanocomposite and Its Photocatalytic Activity for Degradation of Methylene Blue and Malachite Green Dyes Under UV and Natural Sunlight Irradiations. Applied Catalysis B: Environmental, 119-120, 197-206. http://dx.doi.org/10.1016/j.apcatb.2012.02.034

[7] Vinu, R., Polisetti, S. and Madras, G. (2010) Dye Sensitized Visible Light Degradation of Phenolic Compounds. Chemical Engineering Journal, 165, 784-797. http://dx.doi.org/10.1016/j.cej.2010.10.018

[8] Jiang, J., Zhang, X., Sun, P.B. and Zhang, L.Z. (2011) ZnO/BiOI Heterostructures: Photoinduced Charge-Transfer Property and Enhanced Visible-Light Photocatalytic Activity. The Journal of Physical Chemistry C, 115, 20555-20564. http://dx.doi.org/10.1021/jp205925z

[9] Stejskal, J., Kratochvíl, P. and Jenkins, A.D. (1996) The Formation of Polyaniline and the Nature of Its Structures. Polymer, 37, 367-369. http://dx.doi.org/10.1016/0032-3861(96)81113-X

[10] Ohsaka, T., Ohnuki, Y., Oyama, N., Katagiri, G. and Kamisako, K. (1984) IR Absorption Spectroscopic Identification of Electroactive and Electroinactive Polyaniline Films Prepared by the Electrochemical Polymerization of Aniline. Journal of Electroanalytical Chemistry and Interfacial Electrochemistry, 161, 399-405. http://dx.doi.org/10.1016/S0022-0728(84)80198-9

[11] Nohria, R., Khillan, R.K., Su, Y., Dikshit, R., Lvov, Y. and Varahramyan, K. (2006) Humidity Sensor Based on Ultrathin Polyaniline Film Deposited Using Layer-by-Layer Nano-Assembly. Sensors and Actuators B: Chemical, 114, $218-$ 222. http://dx.doi.org/10.1016/j.snb.2005.04.034

[12] Monkman, A.P. and Adams, P. (1991) Optical and Electronic Properties of Stretch-Oriented Solution-Cast Polyaniline Films. Synthetic Metals, 40, 87-96 http://dx.doi.org/10.1016/0379-6779(91)91491-R

[13] Yang, Y. and Heeger, A.J. (1994) Polyaniline as a Transparent Electrode for Polymer Light-Emitting Diodes: Lower Operating Voltage and Higher Efficiency. Applied Physics Letters, 64, 1245-1247. http://dx.doi.org/10.1063/1.110853

[14] Armelin, E., Pla, R., Liesa, F., Ramis, X., Iribarren, J.I. and Alemán, C. (2008) Corrosion Protection with Polyaniline and Polypyrrole as Anticorrosive Additives for Epoxy Paint. Corrosion Science, 50, 721-728. http://dx.doi.org/10.1016/j.corsci.2007.10.006

[15] Kobayashi, T., Yoneyama, H. and Tamura, H. (1984) Polyaniline Film-Coated Electrodes as Electrochromic Display Devices. Journal of Electroanalytical Chemistry and Interfacial Electrochemistry, 419-423. http://dx.doi.org/10.1016/S0022-0728(84)80201-6

[16] Zhu, S.B., Wei, W., Chen, X.N., Jiang, M. and Zhou, Z.W. (2012) Hybrid Structure of Polyaniline/ZnO Nanograss and Its Application in Dye-Sensitized Solar Cell with Performance Improvement. Journal of Solid State Chemistry, 190, 174-179. http://dx.doi.org/10.1016/j.jssc.2012.02.028

[17] Tachibana, H., Yamanaka, Y., Sakai, H., Abe, M. and Matsumoto, M. (2000) J-Aggregate Formation and Morphological Change on UV Irradiation of the Langmuir-Blodgett Films of Spiropyran. Molecular Crystals and Liquid Crystals, 345, 149-154. http://dx.doi.org/10.1080/10587250008023910

[18] Kim, J.H., Ban, S.Y. and Zhang, Q. (2006) Effect of Photocrosslinking on Photochroism of Chalcone-Based Polymeric Materials Bearing Spiropyran Dye. Molecular Crystals and Liquid Crystals, 445, 307/[597]-314/[604].

[19] Ma, S., Kuwahara, Y., Nagano, H., Hatae, N., Ogata, T., Kim, S. and Kurihara, S. (2014) Photo-Controlled Manipulation of Micrometer-Scale Objects on Polyethyleneglycol Thin Films with Azobenzene Compounds. Molecular Crystals 
and Liquid Crystals, 601, 126-133. http://dx.doi.org/10.1080/15421406.2014.944382

[20] Wan, M. (1992) Absorption Spectra of Thin Film of Polyaniline. Journal of Polymer Science Part A: Polymer Chemistry, 30, 543-549. http://dx.doi.org/10.1002/pola.1992.080300404

[21] Patil, S.L., Chougule, M.A., Pawar, S.G., Sen, S. and Patil, V.B. (2012) Effect of Camphor Sulfonic Acid Doping on Structural, Morphological, Optical and Electrical Transport Properties on Polyaniline-ZnO Nanocomposites. Soft Nanoscience Letters, 2, 46-53.

[22] Alam, M., Alandis, N.M., Ansari, A.A. and Shaik, M.R. (2013) Optical and Electrical Studies of Polyaniline/ZnO Nanocomposite. Journal of Nanomaterials, 2013, Article ID: 157810. http://dx.doi.org/10.1155/2013/157810 